\title{
BIAS DEPENDANT NOISE WAVE MODELLING PROCEDURE OF MICROWAVE FETS
}

\author{
Olivera Pronić-Rančić — Zlatica Marinković — Vera Marković *
}

\begin{abstract}
A new noise modelling procedure of microwave field-effect transistors (FETs) valid for various bias conditions is suggested in this paper. The proposed procedure is based on transistor noise wave model. With the aim to improve the noise wave model accuracy, the modification of the model is done by inclusion of the error correction functions into the noise wave model equations. It leads to significant reduction of deviations between measured and simulated noise parameters and therefore better noise prediction is achieved. It is also shown that once determined error correction functions can be applied for accurate noise modelling of the same device for various bias conditions. The validity of the presented noise modelling approach is exemplified by modelling of a specific MESFET device in packaged form.
\end{abstract}

K e y w or d s: MESFET, wave model, noise parameters, bias conditions

\section{INTRODUCTION}

Reliable and accurate small signal and noise models of low noise microwave FETs (MESFETs, HEMTs) are necessary for the design of active circuits in modern communication systems. Therefore, during the last few decades an extensive work has been carried out in the field of signal / noise modelling of microwave transistors. There is a number of different models, starting from accurate physical models which require knowledge about the numerous technological parameters $[1,2]$, through the widely used empirical models, mostly based on equivalent circuit representation of a transistor [3-15], to the models based on the application of the artificial neural networks, based either on the black box modelling approach $[16,17]$ or on a combination with the empirical models [18].

One of the common noise models of microwave transistors most frequently used in microwave circuit simulators is the well-known Pospieszalski's model [5], a twoparameter noise model based on $\mathrm{H}$ representation of transistor intrinsic circuit with two uncorrelated noise sources, the voltage noise source at the gate side and the current noise source at the drain side. An alternative modelling approach, especially efficient in the microwave frequency region is based on treatment of noise in terms of waves, as it allows the use of scattering parameters for noise computations $[9,10]$. The wave approach is useful not only for noise modelling, but also for measurement of microwave FETs [10]. The noise wave modelling procedures of MESFETs/HEMTs and dual-gate MESFETs based on $T$ representation of transistor intrinsic circuit are proposed in [12] and [13].

In [7] it was shown that taking into account correlation of the noise sources in the Pospieszalski's noise model improves the accuracy of the noise modelling. However, further accuracy improvement can be achieved by introducing the frequency dependent error correction functions in expressions defining the device noise parameters [14]. The modelling procedure is similar to that presented in [8] for Fukui's noise model. In [14] and [15] it was shown that the error correction functions calculated for one operating temperature can be used for efficient transistor noise parameters modelling for various device ambient temperatures.

Besides the device temperature, the operating bias conditions alter the device noise performance as well. Therefore, improvements in bias dependant modelling of MESFETs/HEMTs noise parameters have been investigated. MESFET/HEMT noise wave model based on $T$ representation of transistor intrinsic circuit is considered. The more accurate noise wave model is developed by determination and inclusion of the error correction functions into the model equations. Further, it is shown that once determined error correction functions can be applied for accurate noise modelling of the same transistor for various bias conditions. The proposed model provides excellent modelling accuracy which is illustrated by an appropriate modelling example of a packaged MESFET device.

\section{PROPOSED NOISE MODELLING PROCEDURE}

Microwave FET devices in packaged form are considered in this study. Due to the presence of parasitic effects, the equivalent circuit of a packaged transistor is more complex than that of a chip transistor. The equivalent circuit used in this study is shown in Fig. 1. Transistor intrinsic circuit, which is common for the most of microwave FET models, is denoted by the dashed line.

\footnotetext{
* Faculty of Electronic Engineering, University of Niš, Aleksandra Medvedeva 14, Serbia, olivera.pronic@elfak.ni.ac.rs, zlatica.marinkovic@elfak.ni.ac.rs, vera.markovic@elfak.ni.ac.rs
} 


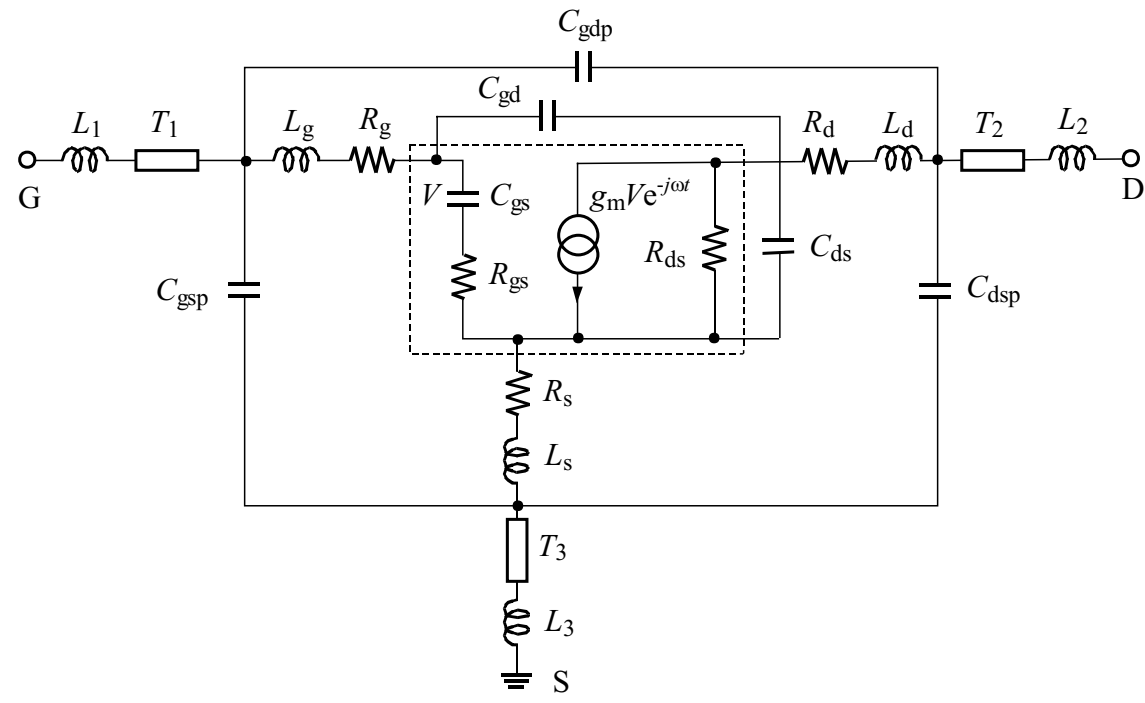

Fig. 1. Equivalent circuit of MESFET/HEMT package

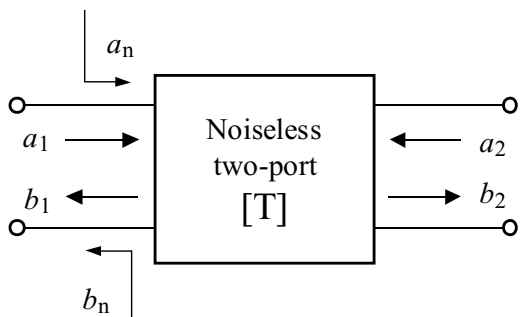

Fig. 2. $2 T$ representation of a linear noisy two-port

The remaining extrinsic elements, embedded in the circuit, represent parasitic effects of device.

A transistor intrinsic circuit (Fig. 1) is a linear noisy two-port network. As it is known, noise in linear two-port networks can be characterized in many different ways, [19]. Any noisy linear two- port can be replaced by a noiseless two-port network and two additional correlated noise sources. Noise is typically characterized using equivalent voltage and/or current sources. Therefore, the impedance and admittance matrix representations, the chain matrix representation and a few others are often used in CAD of noisy networks. On the other hand, in the noise wave representation, a noisy two-port network is described by using a noiseless linear equivalent circuit and the waves that emanate from its ports, [20].

We considered a transistor intrinsic circuit as a noiseless two-port defined by transfer scattering parameters [T] and two noise wave sources, $a_{n}$ and $b_{n}$, referring to the input, as shown in Fig. 2.

The matrix equation describing this representation of the noisy two-port follows

$$
\left[\begin{array}{l}
a_{1} \\
b_{1}
\end{array}\right]=\left[\begin{array}{ll}
T_{11} & T_{12} \\
T_{21} & T_{22}
\end{array}\right]\left[\begin{array}{l}
b_{2} \\
a_{2}
\end{array}\right]+\left[\begin{array}{l}
a_{n} \\
b_{n}
\end{array}\right],
$$

where $a_{i}$ and $b_{i}, i=1,2$, are incident and output waves at the $i$-th port.
Generally, the noise wave sources $a_{n}$ and $b_{n}$ are correlated and characterized by a correlation matrix $C_{T}$, given by

$$
C_{T}=\left[\begin{array}{cc}
\left\langle\left|a_{n}\right|^{2}\right\rangle & \left\langle-a_{n} b_{n}^{*}\right\rangle \\
\left\langle-b_{n} a_{n}^{*}\right\rangle & \left\langle\left|b_{n}\right|^{2}\right\rangle
\end{array}\right],
$$

where \langle\rangle indicates time average of the quantity inside and * indicates complex conjugation. It is very convenient to use the noise wave temperatures as empirical noise model parameters, [12]. In that way, the correlation matrix $C_{T}$ can be expressed by

$$
C_{T}=k \Delta f\left[\begin{array}{cc}
T_{a} & \left|T_{c}\right| e^{j \varphi_{c}} \\
\left|T_{c}\right| e^{-j \varphi_{c}} & T_{b}
\end{array}\right]
$$

where $k$ is the Boltzmann's constant and $\Delta f$ is the noise bandwidth $(\Delta f=1 \mathrm{~Hz}$ is assumed). Now, the noise performance of any two-port network can be completely characterized by two real temperatures $T_{a}$ and $T_{b}$ and a complex correlation temperature $T_{c}=\left|T_{c}\right| e^{j \varphi_{c}}=$ $\left|T_{c}\right| e^{j \omega \tau_{c}}$.

The noise parameters of transistor intrinsic circuit: minimum noise figure $F_{\min i}$, optimum source reflection coefficient $\Gamma_{\mathrm{opt} i}=\left|\Gamma_{\mathrm{opt} i}\right| e^{j \varphi_{\mathrm{opt} i}}$ and normalized noise resistance $r_{n i}$, can be expressed in term of noise wave temperatures as

$$
\begin{aligned}
F_{\min i} & =1+\frac{T_{a}-T_{b}}{2 T_{0}}+\frac{1}{2 T_{0}} \sqrt{\left(T_{a}+T_{b}\right)^{2}-4\left|T_{c}\right|^{2}} \\
\Gamma_{\mathrm{opt} i} & =\left(\frac{T_{a}+T_{b}}{2\left|T_{c}\right|}-\sqrt{\left.\left(\frac{T_{a}+T_{b}}{2\left|T_{c}\right|}\right)^{2}-1\right)}\right) e^{j \omega \tau_{c}}, \\
r_{n i} & =\frac{\left|T_{c}\right|}{4 T_{0}\left|\Gamma_{\mathrm{opt} i}\right|}\left[1+2\left|\Gamma_{\mathrm{opt} i}\right| \cos \varphi_{\mathrm{opt} i}+\left|\Gamma_{\mathrm{opt} i}\right|^{2}\right]
\end{aligned}
$$

where $T_{0}$ is the standard reference temperature $(290 \mathrm{~K})$ and the normalization impedance is $50 \Omega$. After adding of device parasitics, the noise parameters of the complete circuit are computed. 

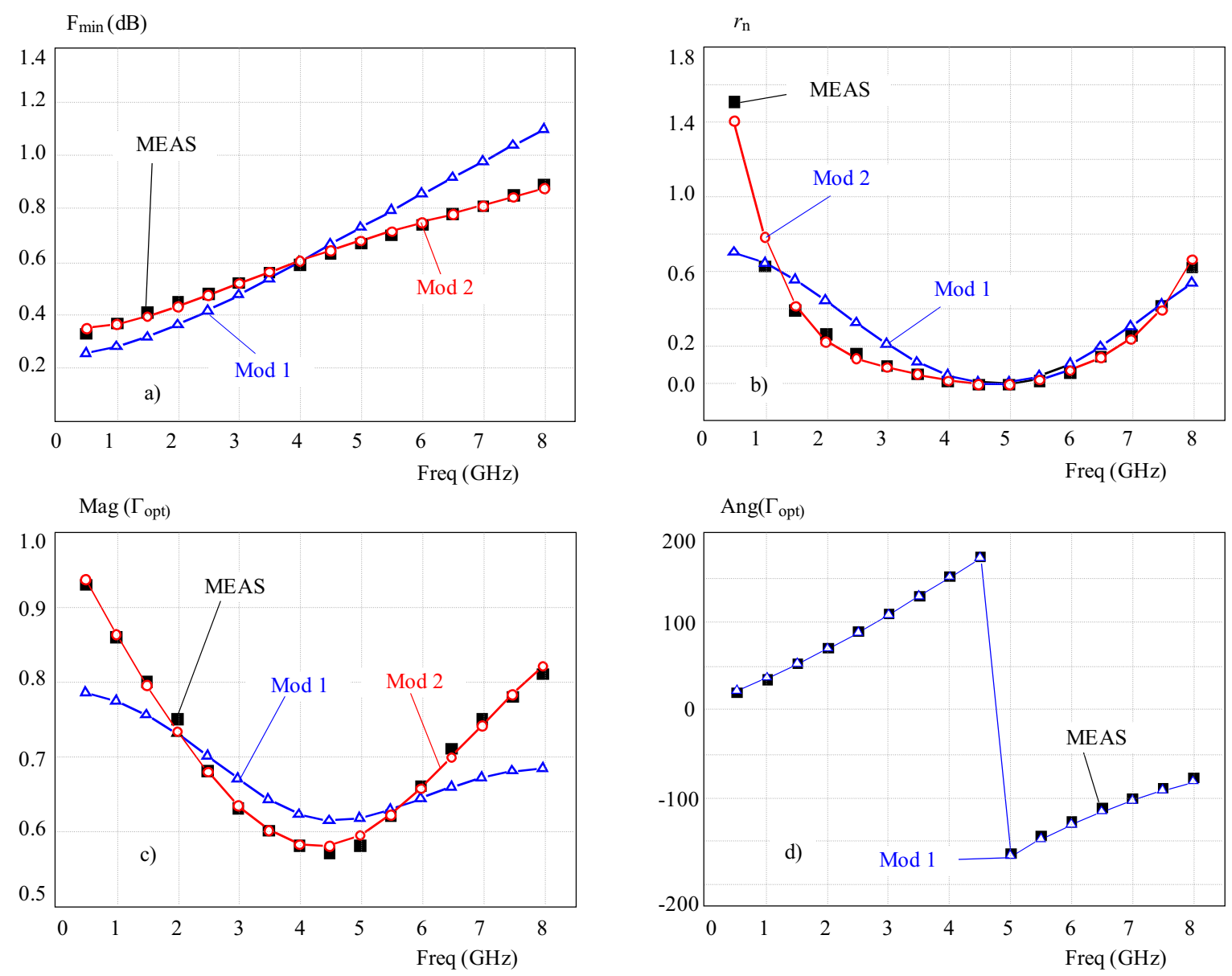

Fig. 3. Noise parameters at $(2 \mathrm{~V}, 20 \mathrm{~mA})$ : (a) - minimum noise figure, (b) - normalized equivalent noise resistance, (c) - magnitude of optimum reflection coefficient, (d)- angle of optimum reflection coefficient

The transistor noise parameters calculated as described above do not perfectly match measured noise parameters. In order to minimize deviations that exist between measured and modelled noise parameters, a correction procedure based on incorporation of frequencydependent error correction functions into the noise equations (4)-(6) is proposed.

With the aim to determine the error correction functions, at the beginning, for each of four noise parameters the ratio of the measured and simulated transistor noise parameters is calculated over the entire frequency range. Then, curve-fitting procedure is applied on these sets of data, in order to obtain suitable frequency dependencies. In that way, corresponding mathematical functions, representing error correction functions, are determined for all four noise parameters. After that, each intrinsic circuit noise parameter obtained by the noise wave approach is multiplied by the corresponding error correction function $y_{i}(f), i=1, \ldots, 4$ and as a result, new equations for transistor intrinsic circuit noise parameters, enabling more accurate noise prediction, are

$$
\begin{aligned}
F_{\min i_{\text {new }}} & =F_{\min i} y_{1}(f), \\
r_{n i_{\text {new }}} & =r_{n i} y_{2}(f), \\
M a g\left(\Gamma_{\mathrm{opt} i}\right)_{\text {new }} & =M a g\left(\Gamma_{\mathrm{opt} i}\right) y_{3}(f), \\
\operatorname{Ang}\left(\Gamma_{\mathrm{opt} i}\right)_{\text {new }} & =\operatorname{Ang}\left(\Gamma_{\mathrm{opt} i}\right) y_{4}(f) .
\end{aligned}
$$

\section{NUMERICAL RESULTS}

Numerical results related to noise modelling of a GaAs FET packaged microwave transistor, type ATF 21186 (by Agilent (HP)), obtained by the proposed procedure, are presented in this paper. Measured values of $S$ and noise parameters for biases $(2 \mathrm{~V}, 10 \mathrm{~mA}),(2 \mathrm{~V}, 15 \mathrm{~mA})$ and $(2 \mathrm{~V}, 20 \mathrm{~mA})$, in the frequency range $(0.5-8) \mathrm{GHz}$ were available from the device datasheet. All simulations were performed using microwave circuit simulator ADS, [21].

At the beginning, the equivalent circuit parameters (equivalent circuit elements and noise wave temperatures) have been extracted from the available measured data and the noise parameters are simulated. As illustration, the simulated noise parameters at bias point $(2 \mathrm{~V}, 20 \mathrm{~mA})$ obtained by the noise wave approach (MOD1) and the corresponding measured data (MEAS) are given in Fig. 3. Inaccuracy in noise modelling, especially for the minimum noise figure and the magnitude of optimum source reflection coefficient can be observed. With the aim to eliminate deviations that exist between measured and modelled values of noise parameters, the error correction functions were determined and included in the transistor noise wave model, as described in previous section. In this case, the error correction functions were determined 

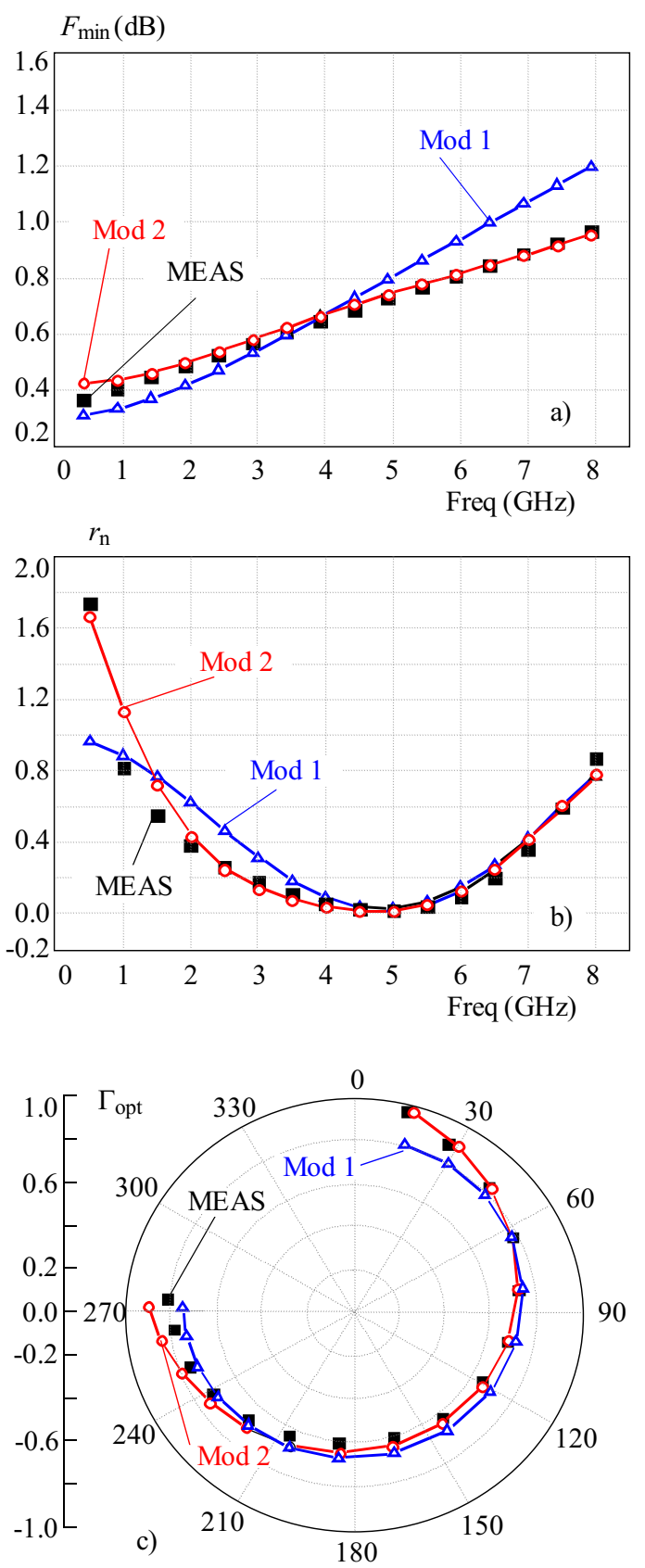

Fig. 4. Noise parameters at $(2 \mathrm{~V}, 10 \mathrm{~mA})$ : (a) - minimum noise figure, (b) - normalized equivalent noise resistance, (c) - optimum reflection coefficient

for the minimum noise figure, normalized noise resistance and magnitude of optimum source reflection coefficient and have the polynomial form

$$
\begin{gathered}
y_{1}(f)=1.43105-0.1335 f+0.0068 f^{2}, \\
y_{2}(f)=3.12205-2.78185 f+1.01299 f^{2} \\
-0.14982 f^{3}+0.00787 f^{4}, \\
y_{3}(f)=1.28048-0.19982+0.03342 f^{2} \\
-0.00122 f^{3} .
\end{gathered}
$$

The simulated values for angle of optimum source reflection coefficient are in excellent agreement with the mea- sured ones and there was no need to include any correction for that parameter in the noise model. The modified frequency dependences of the noise parameters are also shown in Fig. 3 (denoted by MOD2). It is obvious that very good agreement with the measured noise parameters is now achieved.

Further, an investigation has been carried out to in order to verify the reliability of prediction of device noise parameters versus bias by applying the proposed modelling procedure. The previously determined error correction functions have been applied for noise parameters' prediction of the same transistor for all considered biases. As example, the device noise parameters at $(2 \mathrm{~V}, 10 \mathrm{~mA})$ obtained by the basic wave approach (MOD1) and by the suggested technique applying error correction functions determined previously for the bias point $(2 \mathrm{~V}, 20 \mathrm{~mA})$ (MOD2) are shown in Fig. 3. The corresponding measured values (MEAS) are also shown. It is obvious that the presented method provides results that agree much better with the measured data than the basic wave model.

\section{CONCLUSION}

The accuracy of the standard noise wave model of microwave FETs is significantly improved by implementation of frequency-dependent error correction functions in the expressions determining the noise parameters of the device intrinsic circuit, as it is presented in the paper. The corresponding mathematical functions, representing error correction functions, are determined from the ratio of the measured noise parameters and the noise parameters simulated by the noise wave model and by applying suitable curve-fitting procedures on these sets of data. The error correction functions calculated for one bias point are successfully applied for noise parameters' prediction of the same transistor for various bias conditions and this is the main advantage of the proposed improvement procedure. The proposed model provides excelent modelling accuracy, which is illustrated by an appropriate modelling example of a MESFET in packaged form.

\section{Acknowledgement}

This work was supported by the Ministry of Science and Technology Development of Serbia within the project No. TR-32052: Research and development of solutions for performance improvements of wireless communication systems in microwave and millimeter frequency bands.

\section{REFERENCES}

[1] PUCEL, R. A.-HAUS, H. A.—STATZ, H. : Signal and Noise Properties of Gallium Arsenide Microwave Field-Effect Transistors, Advances in Electronics and Electron Physics (1975), $195-265$. 
[2] FUKUI, H.: Design of Microwave GaAs MESFET's for BroadBand Low-Noise Amplifiers, IEEE Trans. Microwave Theory Tech 27 (1979), 643-650.

[3] CAPPy, A.-VANOVERSChElde, A.-SCHORTGEN, A. -VERSNAEYEN, C.-SALMER, G. : Noise Modelling in Submicrometer-Gate Two-Dimensional Electron-Gas Field-Effect Transistors, IEEE Trans. Electron Devices 32 (1985), 2787-2795.

[4] GUPTA, M. S.-PITZALis, O.-ROSENBAUM, S. E.-GREILING, P. T. : Microwave Noise Characterization of GaAs MESFETs: Evaluation by On-Wafer Low-Frequency Output Noise Current Measurement, IEEE Trans. Microwave Theory Tech 35 (1987), 1208-1218.

[5] POSPIESZALSKI, M. W.: Modelling of Noise Parameters of MESFET's and MODFET's and their Frequency and Temperature Dependence, IEEE Trans. Microwave Theory Tech. 37 (1989), 1340-1350.

[6] POSPIESZALSKI, M. W. : Interpreting Transistor Noise, IEEE Microw. Mag. 11 No. 6 (2010), 61-69.

[7] MARKović, V.-MilovanoviĆ, B.-MALEŠ-ILIĆ, N. : MESFET Noise Model Based on Three Equivalent Temperatures, in Proc. 27th European Microwave Conference, Jerusalem, Israel, 1997,, pp. 966-971.

[8] RATNA, P.-KIRTY, V. S. R.: A Novel Technique for Accurate Noise Modeling, Proc. of APMC2001, Taipei, Taiwan,, pp. $730-734$.

[9] HECKEN, R. P.: Analysis of Liner Noisy Two-Ports Using Scattering Waves, IEEE Trans. Microwave Theory Tech. 29 (Oct 1981), 997-1004.

[10] WEDGE, S. W.-RUTLEDGE, D. B.: Wave Techniques for Noise Modelling and Measurement, IEEE Trans. Microwave Theory Tech. 40 (Nov 1992), 2004-2012.

[11] PRONIĆ, O.-MARKOVIĆ, V.-MALEŠ-ILIĆ, N. : The Wave Approach to Noise Modelling of Microwave Transistors by Including the Correlation Effect, Microwave and Optical Technology Letters 28 No. 6 (March 2001), 426-430.

[12] PRONiĆ, O.-MARKOVIĆ, V.-MALEŠ-ILIĆ, N. : MESFET Noise Modelling Based on Noise Wave Temperatures, in Proc. TELSIKS'99, Niš, Yugoslavia, 1999, pp. 407-410.

[13] PRONiĆ, O.-MARKOVIĆ, V.: A Wave Approach to Signal and Noise Modelling of Dual-Gate MESFET, AEÜ - Archiv für Elektronik und Übertragungstechnik (International Journal of Electronics and Communications) 56 No. 1 (Jan 2002), 61-64.

[14] PRONiĆ, O.-MITIĆ, G.-RANELOVIĆ, J.-MARKOVIĆ, V.: Procedure for Accurate Noise Modelling of Microwave FETs Versus Temperature, Electronics Letters 40 No. 24 (2004), 1551-1553.

[15] PRONIĆ-RANIĆ, O.-MARINKOVIĆ, Z.-MARKOVIĆ, V. : An Efficient Procedure for Noise Wave Modelling of Microwave FETs Versus Temperature, Microwave Review 16 No. 2 (Dec 2010), 37-41.

[16] WAtson, P. M.-WEATHERSPOON, M.-DUNLEAVY, L.-CREECH, G. L. : Accurate and Efficient Small-Signal Modelling of Active Devices using Artificial Neural Networks, in Proc. Gallium Arsenide Integrated Circuit Symposium, Nov 1998, pp. 95-98.
[17] MARINKOVIĆ, Z.-PRONIĆ-RANIĆ, O.-MARKOVIĆ, V. : Bias-dependent Models of Microwave Transistors based on PKI Artificial Neural Networks, Proceedings of the European Microwave Association 4 No. 1 (2008), 82-87.

18] MARINKOVIĆ, Z.-MARKOVIĆ, V.: Temperature Dependent Models of Low-Noise Microwave Transistors based on Neural Networks, International Journal for RF and Microwave Computer-Aided Engineering 15 No. 6 (2005), 567-577.

[19] DOBROWOLSKI, J. A.: Introduction to Computer Methods for Microwave Circuit Analysis and Design, Artech House, London, 1991.

[20] MEYS, R. P. : A wave Approach to the Noise Properties of Linear Microwave Devices, IEEE Trans. Microwave Theory Tech. (1978), 34-37.

[21] Advanced Design System-version 1.5, Agilent Eesof EDA, 2000.

Received 14 September 2011

Olivera Pronić-Ranić was born in 1969 in Leskovac, Serbia. She received the Dipl-Ing degree in Electrical Engineering from the Faculty of Electronic Engineering, University of Niš, Serbia, in 1993, and MSc degree and PhD from the same university in 1998 and 2002., respectively. She is currently an Associate Professor at the Department of Telecommunications, at Faculty of Electronic Engineering. Her research interests include modelling of active microwave devices and artificial neural networks and their application in the field of microwaves. Prof. Pronić-Ranić has authored/co-authored two textbooks and more than 90 scientific papers.

Zlatica Marinković was born in 1975 in Vranje, Serbia. She received the Dipl-Ing degree in Electrical Engineering from the University of Niš, Faculty of Electronic Engineering, Serbia in 1999 and the MSc and PhD degrees from same University in 2003 and 2007, respectively. She is a Teaching and Research Assistant with the Universty of Niš, Faculty of Electronic Engineering, Serbia. She has been a Visiting Researcher with the University of Messina, Italy, in 2009 and 2010. Her research areas are: microwave electronics and artificial neural networks and their application in the field of microwaves. She has authored/co-authored more than 70 scientific papers.

Vera Marković was born in 1956 in Niš, Serbia. She received a Dipl-Ing degree in Electrical Engineering in 1980, the MSc degree in 1985 and $\mathrm{PhD}$ degree in 1992, all from the Faculty of Electronic Engineering, University of Niš. She is currently a full professor at the Department for Telecommunications of the Faculty of Electronic Engineering of University of Niš and vice-chair of IEEE Serbia \& Montenegro section. Her current research interests include the modeling of microwave devices for wireless communications, application of neural networks in microwave CAD techniques, the investigation of biological effects of microwave radiation, etc. Prof. Marković has authored or co-authored a monograph, two textbooks and more than 250 conference or journal papers. 